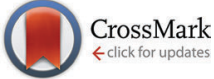

Cite this: Chem. Commun., 2016 52,7886

Received 1st May 2016,

Accepted 23rd May 2016

DOI: $10.1039 / c 6 c c 03627 a$

www.rsc.org/chemcomm

\section{A Z-scheme photocatalyst constructed with an yttrium-tantalum oxynitride and a binuclear Ru(II) complex for visible-light $\mathrm{CO}_{2}$ reduction $\dagger$}

\author{
Kanemichi Muraoka, ${ }^{a}$ Hiromu Kumagai, ${ }^{a}$ Miharu Eguchi, ${ }^{\mathrm{b}}$ Osamu Ishitani ${ }^{* a}$ and \\ Kazuhiko Maeda*a
}

\begin{abstract}
An yttrium-tantalum oxynitride having a band gap of $2.1 \mathrm{eV}$ (absorbing visible light at $<\mathbf{5 8 0} \mathrm{nm}$ ) was applicable as a semiconductor component of a Z-scheme $\mathrm{CO}_{2}$ reduction system operable under visible light, in combination with a binuclear Ru(II) complex that has strong absorption in the visible region ( $<600 \mathrm{~nm}$ ). Excitation of this system with visible light under a $\mathrm{CO}_{2}$ atmosphere induced photocatalytic formation of formic acid with very high selectivity ( $>99 \%$ ).
\end{abstract}

In order to address the depletion of fossil fuels and the concomitant emission of $\mathrm{CO}_{2}$, the chemical fixation of $\mathrm{CO}_{2}$ as well as its conversion into useful compounds are currently important topics in the field of chemistry. Various reactions/ schemes have been proposed to date for this purpose. ${ }^{1-12}$ Among these, photocatalytic $\mathrm{CO}_{2}$ reduction using a heterogeneous photocatalyst that consists of a semiconductor and a metal complex has great potential because it is a readily scalable process that utilizes only low-density sunlight. ${ }^{13}$

From the viewpoint of solar energy conversion, a semiconductor photocatalyst that harvests a wide range of visible light is highly desirable. Recently, it has been reported that certain metal oxides modified with $\mathrm{Ag}$ as a promoter achieved $\mathrm{CO}_{2}$ reduction using water as the electron source. ${ }^{7}$ However, the band gaps of these metal oxides are too large to harvest visible light. While our group has developed heterogeneous photocatalysts for $\mathrm{CO}_{2}$ reduction that consist of a visible-light-responsive semiconductor and a functional metal complex working as an oxidation and a reduction site, respectively, these novel semiconductors (e.g., TaON, $\mathrm{CaTaO}_{2} \mathrm{~N}$ and $\mathrm{C}_{3} \mathrm{~N}_{4}$ ) can harvest visible light only at wavelengths shorter than $500 \mathrm{~nm} \cdot{ }^{9-11}$ Unfortunately, there are very few semiconductors that have a band gap smaller than $2.5 \mathrm{eV}$ (corresponding to $500 \mathrm{~nm}$ wavelength) and that can be

\footnotetext{
${ }^{a}$ Department of Chemistry, School of Science, Tokyo Institute of Technology, 2-12-1-NE-2 Ookayama, Meguro-ku, Tokyo 152-8550, Japan.

E-mail: ishitani@chem.titech.ac.jp, maedak@chem.titech.ac.jp

${ }^{b}$ Electronic Functional Materials Group, Polymer Materials Unit, National Institute for Materials Science, 1-1 Namiki, Tsukuba, Ibaraki 305-0044, Japan

$\dagger$ Electronic supplementary information (ESI) available. See DOI: 10.1039/c6cc03627a
}

applied for photocatalytic $\mathrm{CO}_{2}$ reduction. Reducing the band gap of a semiconductor will reduce the reactivity of electrons and holes generated in the conduction and valence bands, respectively. At the same time, it will become difficult to satisfy thermodynamic requirements; that is, valence and conduction band potentials that straddle the redox potentials of a desired reaction. Because a $\mathrm{CO}_{2}$ fixation system using metal-complex/ semiconductor hybrid photocatalysts ultimately requires the use of water as the electron source, a semiconductor photocatalyst has to satisfy band edge potentials that straddle both the water oxidation and $\mathrm{CO}_{2}$ reduction potentials.

Herein we report that an yttrium-tantalum oxynitride (YTON) having a band gap of $2.1 \mathrm{eV}$ coupled with a binuclear $\mathrm{Ru}$ (II) complex ( $\mathbf{R u R u}$, see Chart 1) works as a photocatalyst for reduction of $\mathrm{CO}_{2}$ to formic acid under visible-light irradiation. This system works according to the Z-scheme principle; i.e., excitation of both YTON and the redox photosensitizer unit of $\mathbf{R u R u} \mathbf{u}^{\prime}$ with visible light induces reduction of $\mathbf{C O}_{2}$ to $\mathrm{HCOOH}$ with $>99 \%$ selectivity at room temperature and ambient atmospheric pressure.

The YTON powder was prepared by the conventional thermal ammonolysis of a corresponding Y-Ta oxide precursor that was previously synthesized using the polymerized complex (PC) method. The details of these two procedures are provided

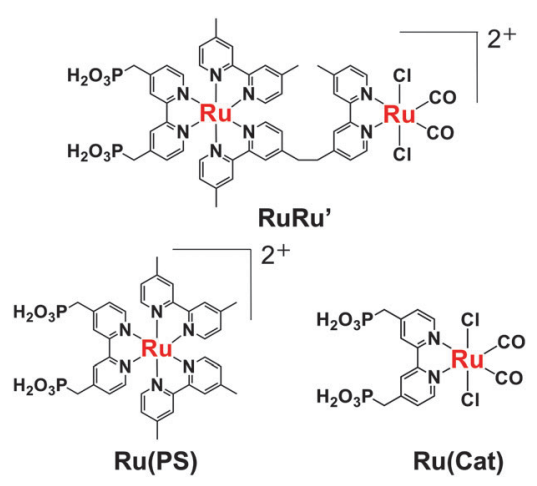

Chart 1 Ruthenium(॥) complexes used in this work. 
in the ESI $\dagger$. The synthesis of single-phase pyrochlore $\mathrm{Y}_{2} \mathrm{Ta}_{2} \mathrm{O}_{5} \mathrm{~N}_{2}$ was confirmed by X-ray diffraction (XRD) analysis (Fig. S1, ESI $\dagger$ ). Energy-dispersive X-ray (EDX) spectroscopy and thermogravimetric (TG) analysis of the as-prepared YTON determined that the Y/Ta ratio was 0.95 , and that the concentration of nitrogen in the material was $1.2 \mathrm{wt} \%$, values that were below the theoretical values $(\mathrm{Y} / \mathrm{Ta}=1$, $\mathrm{N}: 4.3 \mathrm{wt} \%$ ), indicating a non-stoichiometric composition. TEM observations showed that the YTON consisted of $20-30 \mathrm{~nm}$ primary particles connected to one another to form larger secondary particles with porous structures (Fig. 1A). The specific surface area of the YTON was determined by nitrogen adsorption/ desorption to be $16 \mathrm{~m}^{2} \mathrm{~g}^{-1}$, a result that can be attributed to its porous structure. As shown in Fig. 1B, the YTON had an absorption edge at approximately $580 \mathrm{~nm}$, consistent with an earlier report. ${ }^{14}$ The band gap of the material was estimated to be about $2.1 \mathrm{eV}$ based on the onset wavelength of its diffuse reflectance spectrum.

$\mathrm{Li}$ et al. have reported that yttrium-tantalum oxynitride exhibits photocatalytic activity for both water reduction and oxidation under visible light. ${ }^{14}$ However, the band-edge potentials of the material have not been reported and remain unclear. Therefore, we conducted photoelectrochemical analyses in order to investigate the band-gap structure. ${ }^{15}$ The actual band-edge positions were evaluated by measuring the onset potentials of photocurrents generated from an $\mathrm{IrO}_{2} / \mathrm{TiO}_{2} / \mathrm{YTON} / \mathrm{FTO}$ electrode in electrolyte solutions with various $\mathrm{pH}$ values. In these experiments, the YTON was immobilized on the FTO by a conventional squeegee method and a $\mathrm{TiO}_{2}$ layer was deposited to improve the inter-particle electron transfer and particle/substrate electron transfer. ${ }^{15 a, 16}$ In addition, colloidal $\mathrm{IrO}_{2}$ was deposited on the $\mathrm{TiO}_{2} /$ YTON to enhance the water oxidation. ${ }^{16 b}$

Current-voltage curves were acquired under chopped visible light irradiation $(\lambda>500 \mathrm{~nm})$, scanning from negative to positive potential at $5 \mathrm{mV} \mathrm{s}{ }^{-1}$ in an aqueous $\mathrm{Na}_{2} \mathrm{SO}_{4}$ solution adjusted to $\mathrm{pH} 4.8,8.7$ or 11.7 by the addition of $\mathrm{H}_{2} \mathrm{SO}_{4}$ or $\mathrm{NaOH}$. As shown in Fig. S2 (ESI $\dagger$ ), an anodic photocurrent attributed to water oxidation was observed under all $\mathrm{pH}$ conditions examined, indicating that the YTON functions as an n-type semiconductor. The onset potential, corresponding to the flat-band potential $\left(E_{\mathrm{FB}}\right)$, was shifted to the negative direction with increasing $\mathrm{pH}$. The energy difference between the conduction band edge potential $\left(E_{\mathrm{CB}}\right)$ and the $E_{\mathrm{FB}}$ is believed to be approximately $0.1-0.3 \mathrm{eV}$ based on the n-type semiconducting character
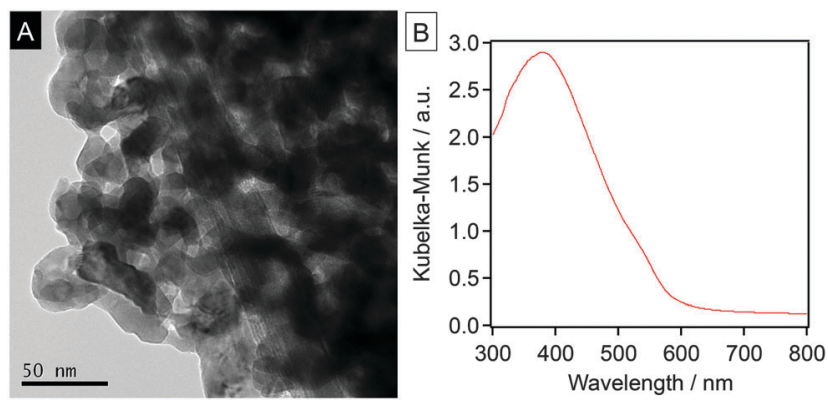

Fig. 1 (A) TEM image, and (B) UV-visible diffuse reflectance spectrum of the as-prepared YTON.

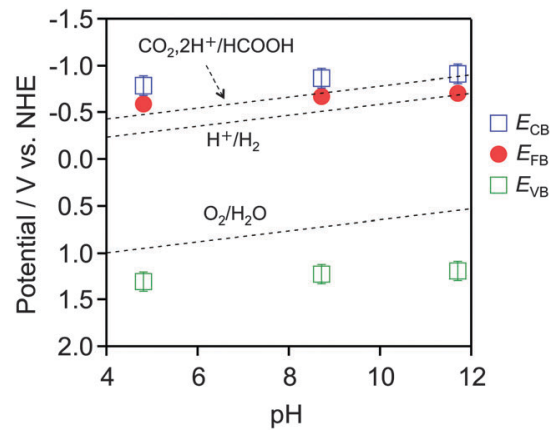

Fig. 2 Dependence of conduction and valence band edge potentials for the as-prepared YTON on the $\mathrm{pH}$ of the electrolyte, as determined from photocurrent measurements (see Fig. S2, ESI $\dagger$ )

of the YTON. ${ }^{17}$ On the basis of the YTON band gap (2.1 eV), the valence band edge potential $\left(E_{\mathrm{VB}}\right)$ can be estimated to be $2.1 \mathrm{~V}$ more positive than $E_{\mathrm{CB}}$. Fig. 2 presents the conduction and valence band edge potentials of the $\mathrm{IrO}_{2} / \mathrm{TiO}_{2} / \mathrm{YTON} / \mathrm{FTO}$ electrode as a function of $\mathrm{pH}$. The positions of the YTON conduction band minimum and the valence band maximum evidently vary with $\mathrm{pH}$, and were shifted at a rate of approximately $-17 \mathrm{mV}$ per $\mathrm{pH}$ as the $\mathrm{pH}$ increased. It was thus shown that YTON had band-edge potentials suitable for water oxidation in all $\mathrm{pH}$ range examined. Under basic $\mathrm{pH}$ conditions, however, it is clear that the driving force for $\mathrm{CO}_{2}$ reduction becomes insufficient.

Prior to photocatalytic reaction, the YTON was modified with both Ag and RuRu' having methylphosphonic-acid anchoring groups, which, respectively, work as a promoter for interfacial electron transfer and as another photocatalytic unit with high capability for $\mathrm{CO}_{2}$ reduction. ${ }^{10 b, 11}$ TEM observations indicated that metallic Ag nanoparticles approximately $10 \mathrm{~nm}$ in size were distributed on the YTON surface (Fig. 3A). The resulting lattice fringe had a period of 0.24 (Fig. 3B), consistent with the $d$ spacing of $\mathrm{Ag}(111)$ planes. The successful immobilization of

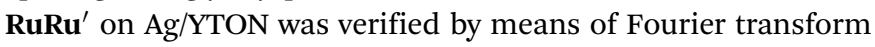
infrared (FT-IR) spectroscopy (Fig. S3, ESI $\dagger$ ).

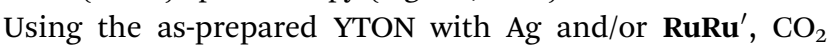
reduction was performed under visible light irradiation $(\lambda>$ $400 \mathrm{~nm}$ ). The reaction setup used in this work was identical to that we have reported previously. ${ }^{10,11}$ Table 1 summarizes the results. To avoid complications resulting from water oxidation catalysis,

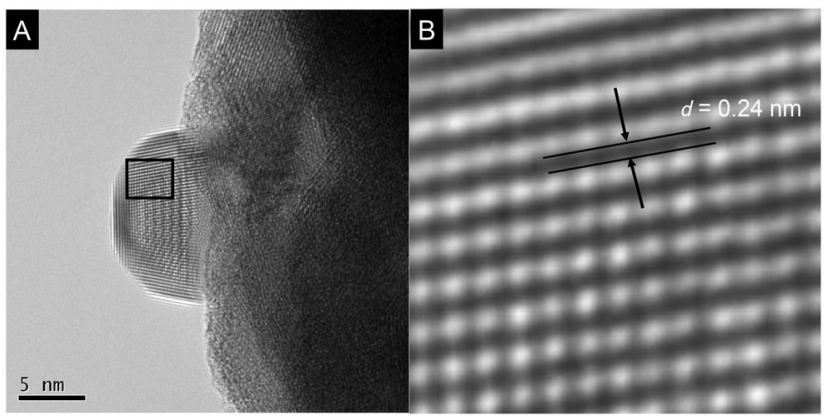

Fig. 3 TEM images of $\mathrm{Ag}(1.5 \mathrm{wt} \%) / \mathrm{YTON}$. Panel B shows a magnified image of the square in panel $A$. 
Table 1 Results of visible-light $\mathrm{CO}_{2}$ reduction using YTON with various modifications $(\lambda>400 \mathrm{~nm})^{a}$

\begin{tabular}{|c|c|c|c|c|}
\hline Entry & Photocatalyst & $\begin{array}{l}\text { Amount of } \\
\mathrm{HCOOH} / \mathrm{nmol}\end{array}$ & TON & Selectivity \\
\hline 1 & RuRu'/YTON & 162 & 5 & $>99$ \\
\hline 2 & RuRu'/Ag/YTON & 630 & 18 & $>99$ \\
\hline 3 & YTON & N.D. & - & - \\
\hline 4 & $\mathrm{Ag} / \mathrm{YTON}$ & N.D. & - & - \\
\hline 5 & $\mathbf{R u R u}^{\prime}(6.0 \mu \mathrm{M})$ & N.D. & - & - \\
\hline $6^{b}$ & $\mathbf{R u R u}^{\prime} / \mathrm{Ag} / \mathrm{YTON}$ & N.D. & - & - \\
\hline $7^{c}$ & $\mathbf{R u R u} / \mathrm{Ag} / \mathrm{YTON}$ & N.D. & - & - \\
\hline $8^{d}$ & $\mathbf{R u R u}^{\prime} / \mathrm{Ag} / \mathrm{YTON}$ & N.D. & - & - \\
\hline 9 & $\mathbf{R u}(\mathbf{P S}) / \mathrm{Ag} / \mathrm{YTON}$ & N.D. & - & - \\
\hline 10 & $\mathbf{R u}($ Cat $) / \mathrm{Ag} / \mathrm{YTON}$ & N.D. & - & - \\
\hline
\end{tabular}

${ }^{a}$ Reaction conditions: photocatalyst, $8.0 \mathrm{mg}$ (Ag $1.5 \mathrm{wt} \%$ ); solution, a mixture of DMA and TEOA ( $4: 1 \mathrm{v} / \mathrm{v}) 4.0 \mathrm{~mL}$; light source, $400 \mathrm{~W}$ highpressure $\mathrm{Hg}$ lamp (SEN) with a $\mathrm{NaNO}_{2}$ solution filter. Reaction time: $24 \mathrm{~h}$. The amount of metal complex loaded in each case was $4.5 \mu \mathrm{mol} \mathrm{g}^{-1}$. ${ }^{b}$ Under an Ar atmosphere. ${ }^{c}$ Without TEOA. ${ }^{d}$ In the dark.

reactions were conducted in a mixed $N, N$-dimethylacetamide (DMA)/triethanolamine (TEOA) solution (4:1 v/v), where TEOA worked as a sacrificial electron donor.

Combining YTON with RuRu' resulted in clearly observable $\mathrm{HCOOH}$ production with very high selectivity (>99\%) and catalytic turnover numbers $\left(\mathrm{TON}_{\mathrm{HCOOH}}\right)$ of 5 based on the amount of loaded RuRu' (entry 1). The Ag-modification increased the $\mathrm{HCOOH}$ formation $\left(\mathrm{TON}_{\mathrm{HCOOH}}=18\right.$, entry 2$)$. This is attributed to the promotional effect of the $\mathrm{Ag}$, which facilitates interfacial electron transfer from the semiconductor to the excited state of the binuclear $\mathrm{Ru}(\mathrm{II})$ complex, ${ }^{10 b, 11}$ as discussed below. The generation of $\mathrm{HCOOH}$ over $\mathbf{R u R u} / \mathrm{Ag} / \mathrm{YTON}$ was improved with increases in the amount of $\mathrm{Ag}$ loaded, up to $1.5 \mathrm{wt} \%$, beyond which the yield began to decrease (Fig. S4, ESI $\dagger$ ). By contrast, neither the YTON nor the Ag/YTON showed activity for the reaction (entries 3 and 4). Note that TEOA

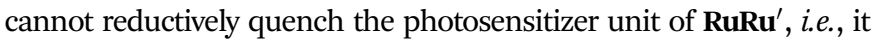

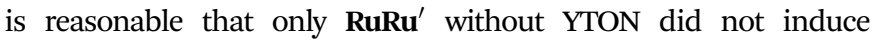
photocatalytic reduction of $\mathrm{CO}_{2}$ (entry 5 in Table 1). In the absence of $\mathrm{CO}_{2}$ or TEOA, no $\mathrm{HCOOH}$ production was observed (entries 6 and 7 ), nor was there any reaction under dark conditions (entry 8). It should be noted that neither $\mathrm{CO}$ nor $\mathrm{H}_{2}$ gas evolution was observed in all cases. No $\mathrm{C}-\mathrm{C}$ coupling product (e.g., ethane and ethanol) was detected as well. These results show that both YTON and $\mathbf{R u R u}$ ' are essential to realize $\mathrm{HCOOH}$ production, and that TEOA works as an electron donor to scavenge holes in the valence band of the YTON.

When using Ag/YTON modified with either a model mononuclear complex of the redox photosensitizer unit (Ru(PS)) or the catalytic model complex (Ru(Cat)), no $\mathrm{HCOOH}$ production could be detected (entries 9 and 10). Ru(Cat) has been shown to function as a cocatalyst for $\mathrm{CO}_{2}$ reduction to generate $\mathrm{HCOOH}$ on certain semiconductors (such as $\mathrm{C}_{3} \mathrm{~N}_{4}$ and $\mathrm{CaTaO}_{2} \mathrm{~N}$ ), ${ }^{9,10 b}$ but it was evidently not effective in conjunction with YTON, probably because of the lower conduction-band potential.

Fig. 4 presents an energy diagram for $\mathbf{R u R u}$ /YTON based on the results of photoelectrochemical measurements (Fig. 2) and our previous study. ${ }^{10 a}$ Upon visible light irradiation $(\lambda>400 \mathrm{~nm})$, both the YTON and the photosensitizing unit of the RuRu'

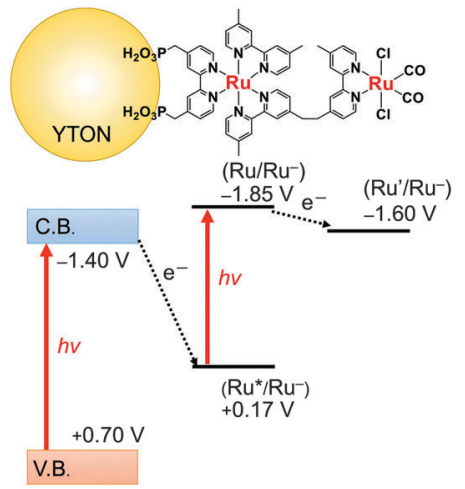

Fig. 4 Energy diagram of RuRu'/YTON.

undergo excitation. In this case, it should be noted that electron transfer from the excited state of $\mathbf{R u R u}\left(E_{\mathrm{ox}}{ }^{*}=-1.30 \mathrm{~V}\right)$ to the conduction band of the YTON $(-1.40 \mathrm{~V})$ is energetically unfavourable. This energy diagram explains the observation that $\mathbf{R u}(\mathbf{C a t}) / Y T O N$ did not promote the photocatalysis of the $\mathrm{CO}_{2}$ reduction (Table 1, entry 10), because the electron transfer from the conduction band of YTON $(-1.40 \mathrm{~V})$ to Ru(Cat) $(-1.60 \mathrm{~V})$ is energetically unfavourable. Conversely, the driving force for electron transfer from the conduction band of YTON to the excited state of $\mathbf{R u R \mathbf { u } ^ { \prime }}(+0.17 \mathrm{~V})$ is very large (i.e., $\left.\Delta E=1.57 \mathrm{~V}\right)$. This reductive electron transfer path appears to be the key to achieving $\mathrm{CO}_{2}$ reduction. In fact, we were able to observe reductive electron transfer by investigating the lifetime of the excited state of $\mathbf{R u}(\mathbf{P S})$ immobilized on the Ag/YTON surface. Fig. 5 presents the emission decay curves of $\mathbf{R u ( P S )}$ adsorbed on YTON with various loading amounts of $\mathrm{Ag}$ during excitation at $\lambda_{\text {ex }}=444 \mathrm{~nm}$. In these experiments, both the YTON and $\mathbf{R u ( P S )}$ underwent photoexcitation, and increasing the loading amount of $\mathrm{Ag}$ accelerated the emission decay of the excited state of $\mathbf{R u}(\mathbf{P S})$. It is noteworthy that oxidative quenching of the excited state of the Ru(PS) did not occur, as discussed above. Previously, we have confirmed that electron- and/or energy-transfer from the excited state of $\mathbf{R u}(\mathbf{P S})$ to $\mathrm{Ag}$ is negligible. ${ }^{11}$ Therefore, the evidently enhanced emission quenching is attributed to the acceleration of the reductive quenching of the excited state of $\mathbf{R u ( P S )}$ by YTON as well as facilitation of the interfacial electron transfer between the YTON and Ru(PS) by the added Ag.

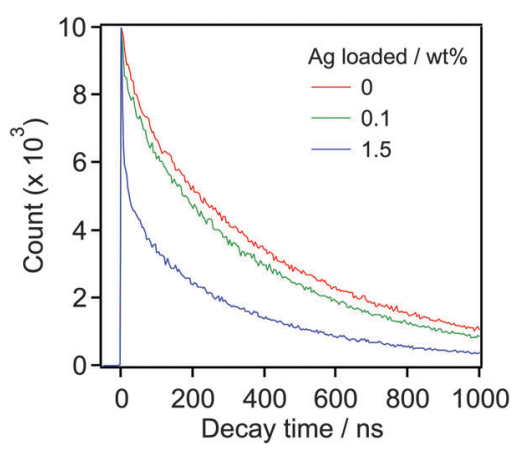

Fig. 5 Emission decay profiles of $\mathrm{Ru}(\mathrm{PS}) / \mathrm{Ag} / \mathrm{YTON}$ with different $\mathrm{Ag}$ loading in MeCN. 
In any photocatalytic $\mathrm{CO}_{2}$ reduction experiments, it is essential to investigate the origin of the carbon source(s) in the reaction product(s), because these may result from surface contaminants such as hydrocarbons and organic acids. ${ }^{18}$ Therefore, we performed the reduction of ${ }^{13} \mathrm{C}$-labeled $\mathrm{CO}_{2}$ in a similar manner to the previous trials. After $60 \mathrm{~h}$ of visible light irradiation, the reacted suspension was filtered and the supernatant was analysed by ${ }^{1} \mathrm{H}$ NMR spectroscopy. As shown in Fig. S5 (ESI $\dagger$ ), a doublet centred at $\delta=8.42 \mathrm{ppm}$ with a coupling constant of $J^{13}{ }_{\mathrm{CH}}=192 \mathrm{~Hz}$ was observed, attributed to a proton bound to the ${ }^{13} \mathrm{C}$ atom in $\mathrm{H}^{13} \mathrm{COOH}$. The observed coupling constant is consistent with that reported in our previous work. ${ }^{9 a}$ In addition to the doublet, a singlet peak appeared at $\delta=8.42 \mathrm{ppm}$, which was attributed to $\mathrm{H}^{12} \mathrm{COOH}$. This singlet was also observed when the reaction was conducted in the dark, indicating that $\mathrm{H}^{12} \mathrm{COOH}$ detected was not generated photocatalytically but rather resulted from contaminants, as indicated by our previous study. ${ }^{10 b}$ Here, approximately $50 \%$ of $\mathrm{HCOOH}$ generated came from $\mathrm{CO}_{2}$. XRD analysis also showed that no change in the XRD pattern of RuRu/Ag/YTON before and after reaction (Fig. S1, $\mathrm{ESI}_{\dagger} \dagger$ ). On the basis of these results, it is

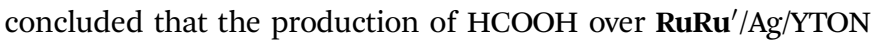
hybrid proceeds via $\mathrm{CO}_{2}$ reduction driven by the two-step photoexcitation of both YTON and the light-harvesting Ru complex in $\mathbf{R u R u}$.

In summary, we developed a new semiconductor material for a Z-scheme photocatalyst coupled with a binuclear $\mathrm{Ru}$ (II) complex, i.e., an yttrium-tantalum oxynitride having a band gap of $2.1 \mathrm{eV}$. This hybrid photocatalyst can reduce $\mathrm{CO}_{2}$ to $\mathrm{HCOOH}$ with a very high selectivity (>99\%).

This work was supported by the PRESTO/JST program "Chemical Conversion of Light Energy" and a Grant-in-Aid for Young Scientists (A) (Project 16H06130). The support from a Grant-in-Aid for Scientific Research on Innovative Area "Artificial Photosynthesis (AnApple)" (JSPS), the Photon and Quantum Basic Research Coordinated Development Program (MEXT, Japan), and a CREST program (JST) is also gratefully acknowledged. Finally, K. M. wishes to thank the Noguchi Institute and the Murata Science Foundation for financial support.

\section{Notes and references}

1 (a) T. Ohkawara, K. Suzuki, K. Nakano, S. Mori and K. Nozaki, J. Am. Chem. Soc., 2014, 136, 10728-10735; (b) T. Suga, H. Mizuno, J. Takaya and N. Iwasawa, Chem. Commun., 2014, 50, 14360-14363.

2 G. Qi, Y. Wang, L. Estevez, X. Duan, N. Anako, A. A. Park, W. Li, C. W. Jones and E. P. Giannelis, Energy Environ. Sci., 2011, 4, 444-452.
3 (a) H. Hori, F. Johnson, K. Koike, O. Ishitani and T. Ibusuki, J. Photochem. Photobiol., A, 1996, 96, 171-174; (b) J. Smieja and C. P. Kubiak, Inorg. Chem., 2010, 49, 9283-9289; (c) L. W. Christina, C. Jim and W. K. Matthew, Nature, 2014, 508, 504-507.

4 (a) T. Arai, S. Sato, T. Kajino and T. Morikawa, Energy Environ. Sci., 2013, 6, 1274-1282; (b) G. Sahara, R. Abe, M. Higashi, T. Morikawa, K. Maeda, K. Ueda and O. Ishitani, Chem. Commun., 2015, 51, 10722-10725; (c) U. Kang, S. K. Choi, D. J. Ham, S. M. Ji, W. Choi, D. S. Han, A. Abdel-Wahab and H. Park, Energy Environ. Sci., 2015, 8, 2638-2643.

5 C. Liu, J. J. Gallagher, K. K. Sakimoto, E. M. Nichols, C. J. Chang, M. C. Y. Chang and P. Yang, Nano Lett., 2015, 15, 3634-3639.

6 (a) J. Hawecker, J. M. Lehn and R. Ziessel, J. Chem. Soc., Chem. Commun., 1983, 9, 536-538; (b) H. Takeda, K. Koike, H. Inoue and O. Ishitani, J. Am. Chem. Soc., 2008, 130, 2023-2031; (c) S. Matsuoka, K. Yamamoto, T. Ogata, M. Kusaba, N. Nakashima, E. Fujita and S. Yanagida, J. Am. Chem. Soc., 1993, 115, 601-609; (d) H. Takeda, H. Koizumi, K. Okamoto and O. Ishitani, Chem. Commun., 2014, 50, 1491-1493; (e) H. Takeda, K. Ohashi, A. Sekine and O. Ishitani, J. Am. Chem. Soc., 2016, 138, 4354-4357.

7 (a) K. Iizuka, T. Wato, Y. Miseki, K. Saito and A. Kudo, J. Am. Chem. Soc., 2011, 133, 20863-20868; (b) K. Teramura, X. Wang, S. Hosokawa, Y. Sakata and T. Tanaka, Chem. - Eur. J., 2014, 20, 9906-9909.

8 S. Sato, T. Morikawa, S. Saeki, T. Kajino and T. Motohiro, Angew. Chem., Int. Ed., 2010, 49, 5101-5105.

9 (a) K. Maeda, K. Sekizawa and O. Ishitani, Chem. Commun., 2013, 49, 10127-10129; (b) K. Maeda, R. Kuriki, M. Zhang, X. Wang and O. Ishitani, J. Mater. Chem. A, 2014, 2, 15146-15151; (c) R. Kuriki, K. Sekizawa, O. Ishitani and K. Maeda, Angew. Chem., Int. Ed., 2015, 54, 2406-2409; (d) K. Maeda, R. Kuriki and O. Ishitani, Chem. Lett., 2016, 45, 182-184; (e) R. Kuriki, O. Ishitani and K. Maeda, ACS Appl. Mater. Interfaces, 2016, 8, 6011-6018.

10 (a) K. Sekizawa, K. Maeda, K. Domen, K. Koike and O. Ishitani, J. Am. Chem. Soc., 2013, 135, 4596-4599; (b) F. Yoshitomi, K. Sekizawa, K. Maeda and O. Ishitani, ACS Appl. Mater. Interfaces, 2015, 7, 13092-13097; (c) A. Nakada, T. Nakashima, K. Sekizawa, K. Maeda and O. Ishitani, Chem. Sci., 2016, DOI: 10.1039/C6SC00586A.

11 R. Kuriki, H. Matsunaga, T. Nakashima, K. Wada, A. Yamakata, O. Ishitani and K. Maeda, J. Am. Chem. Soc., 2016, 138, 5159-5170.

12 (a) S. Wang, W. Yao, J. Lin, Z. Ding and X. Wang, Angew. Chem., Int. Ed., 2014, 53, 1034-1038; (b) S. Wang and X. Wang, Angew. Chem., Int. Ed., 2016, 55, 2308-2320; (c) J. Qin, S. Wang, H. Ren, Y. Hou and X. Wang, Appl. Catal., B, 2015, 179, 1-8.

13 (a) K. Maeda and K. Domen, J. Phys. Chem. Lett., 2010, 1, 2655-2661; (b) Y. Yamazaki, H. Takeda and O. Ishitani, J. Photochem. Photobiol., C, 2015, 25, 106-137.

14 M. Liu, W. You, Z. Lei, G. Zhou, J. Yang, G. Wu, G. Ma, G. Luan, T. Takata, M. Hara, K. Domen and C. Li, Chem. Commun., 2004, 2192-2193.

15 (a) K. Maeda and K. Domen, J. Catal., 2014, 310, 67-74; (b) A. Ishikawa, T. Takata, J. N. Kondo, M. Hara and K. Domen, J. Phys. Chem. B, 2004, 108, 11049-11053; (c) K. Ogisu, A. Ishikawa, Y. Shimodaira, T. Takata, H. Kobayashi and K. Domen, J. Phys. Chem. C, 2008, 112, 11978-11984.

16 (a) N. Nishimura, B. Raphael, K. Maeda, L. Le Gendre, R. Abe, J. Kubota and K. Domen, Thin Solid Films, 2010, 518, 5855-5859; (b) K. Maeda and K. Domen, Angew. Chem., Int. Ed., 2012, 51, 9865-9869.

17 (a) D. E. Scaife, Sol. Energy, 1980, 25, 41-54; (b) Y. Matsumoto, J. Solid State Chem., 1996, 126, 227-234.

18 T. Yui, A. Kan, C. Saitoh, K. Koike, T. Ibusuki and O. Ishitani, ACS Appl. Mater. Interfaces, 2011, 3, 2594-2600. 